\title{
Effect of the new contract on GPs' working lives and perceptions of quality of care: a longitudinal survey
}

\author{
Diane Whalley, Hugh Gravelle and Bonnie Sibbald
}

\begin{abstract}
Background

An ambitious pay-for-performance system was implemented in UK general practice in 2004 amid doubts that it could improve both the working lives of doctors and quality of care.

Aim

To evaluate doctors' perceptions of their working lives and quality of care before and after the new contract.

Design of study

Longitudinal questionnaire survey.

Setting

England, UK.

Method

A longitudinal postal survey of English GPs in February 2004 and September 2005. Measures included reported job satisfaction (7-point scale), hours worked, income, and impact of the contract.

Results

Responses were available from 2105 doctors in 2004 and 1349 in 2005. Mean overall job satisfaction increased from 4.58 out of 7 in 2004 to 5.17 in 2005. The greatest improvements in satisfaction were with remuneration and hours of work. Mean reported hours worked fell from 44.5 to 40.8 . Mean income increased from an estimated £73 400 in 2004 to $£ 92600$ in 2005 Most GPs reported that the new contract had increased their income (88\%), but decreased their professional autonomy $(71 \%)$, and increased their administrative (94\%) and clinical (86\%) workloads. After the introduction of the contract doctors were more positive than they had anticipated about its impact on quality of care.

\section{Conclusion}

GPs' job satisfaction increased after the introduction of the new contract, despite perceptions of negative consequences for workload and autonomy. GPs reported working fewer hours with a higher income, and their expectations regarding the impact of the contract on quality of care had been exceeded.

\section{Keywords}

job satisfaction; primary care; quality of health care; workforce.
\end{abstract}

\section{INTRODUCTION}

The new general medical services (GMS) contract introduced in the UK in April 2004 was heralded as the boldest proposal of its kind ever attempted anywhere. ${ }^{1}$ General practices can now earn up to $20 \%$ of additional income by satisfying a number of performance indicators contained in a Quality and Outcomes Framework (QOF), which relate principally to chronic disease management and organisational aspects of care. The contract further promised to enhance flexibility in the way services were provided and enabled GPs to opt out of responsibility for out-of-hours care. The aim was to improve working lives for GPs as well as quality of care for patients. ${ }^{2}$

A survey conducted in the West Midlands region of England before the introduction of the contract indicated that GPs were doubtful that it would deliver its intended benefits. ${ }^{3}$ There was some optimism that it would improve quality of care, particularly in the light of improvements leading up to its implementation. ${ }^{4}$ However, this was set against concerns for potential negative consequences for non-incentivised conditions. ${ }^{5,6}$ Pay-for-performance

D Whalley, MPhil, research fellow; B Sibbald, PhD, professor of health services research, National Primary Care Research and Development Centre, University of Manchester, Manchester. H Gravelle, PhD, professor of economics, National Primary Care Research and Development Centre, Centre for Health Economics, University of York, York.

Address for correspondence

Diane Whalley, National Primary Care Research and Development Centre, Williamson Building, University of Manchester, Oxford Road, Manchester M13 9PL. Email: diane.whalley@manchester.ac.uk

Submitted: 4 April 2007; Editor's response: 19 June 2007; final acceptance: 20 September 2007.

() British Journal of General Practice 2008; 58: 8-14. DOI: 10.3399/bjgp08X263758 
schemes, such as that found in the QOF element of the contract, may additionally threaten physicians' sense of autonomy and job satisfaction, ${ }^{7}$ which may, in turn, affect performance. A survey with a random national sample of GPs in England in February 2004 indicated that doctors were pessimistic about the prospects for working life under the new contract, with the overwhelming majority expecting their workload to increase and their professional autonomy to decrease. ${ }^{8}$ Despite such apprehensions, GPs' overall job satisfaction was relatively high, and considerably improved from the low point of $2001 .^{9}$ They further expected that many aspects of quality of care for patients would improve under the new contract, although nearly one-third thought that care for patients with acute conditions would deteriorate. ${ }^{8}$

So, has the contract achieved its dual aim of enhanced quality of care and improved working lives - can 'we have our cake and eat it' as one editorial asked? ${ }^{10} \mathrm{~A}$ national panel of English GPs surveyed before (February 2004) and after (September 2005) the implementation of the new contract provided the opportunity to explore this question from the doctors' perspective, specifically to evaluate their job satisfaction, and their perceptions of the impact of the contract on their working life and quality of care.

\section{METHOD}

\section{Participants}

The data are drawn from a postal survey questionnaire administered to a longitudinal panel of GPs in March 2001, February 2004, and September 2005. The methods and findings from the 2001 and 2004 surveys have been reported previously. ${ }^{9,11}$

The main analysis used GPs who responded to the 2004 and 2005 surveys. The 2004 sample comprised 4066 GPs: 1950 who were randomly sampled from the 2002 GMS statistics database ${ }^{12}$ and a further 2116 GPs who had been included in the 2001 survey. A total of 2179 GPs (53.6\%) responded in 2004. Of these, 2122 could be identified in the 2004 GMS statistics database ${ }^{13}$ and were included in the 2005 survey. In 20051378 (64.9\%) GPs responded, 20 of whom were excluded from the 2005 data because of inconsistencies in age, sex, or ethnicity.

The analysis was restricted to contracted GPs (principals, salaried, or locum): 2105 in 2004 and 1349 in 2005. To track changes in this panel before 2004 , the analysis also used the 2001 data available from 986 of these GPs.

\section{Measures}

Job satisfaction was measured with a reduced

\section{How this fits in}

The new 2004 contract sought to enhance working lives for GPs as well as

improve quality of care for patients. Immediately prior to the contract's

introduction, GPs' job satisfaction was higher than it had been in 2001 but they

had concerns about workload and professional autonomy under the contract.

This study has shown that job satisfaction has continued to increase with the

introduction of the contract, despite perceived negative consequences for

workload and autonomy. GPs report working fewer hours and earning a higher

income, and their expectations regarding quality of care under the contract

have been exceeded.

version of the Warr-Cook-Wall job satisfaction measure, with overall and job-facet satisfaction measured on 7-point scales ranging from 'extremely dissatisfied' (scored 1) to 'extremely satisfied' (scored 7). ${ }^{14}$ Job pressure was measured with 20 job stressor items used in similar surveys. ${ }^{15,16}$ Each item was rated from 'no pressure' (scored 1) to 'high pressure' (scored 5). A mean overall job pressure score was derived for GPs who responded to at least half of the stressor items. Other questions included age, sex, contract status (principal, salaried), and number of hours per week typically worked as a GP and on call. GPs were asked all the above questions in each of the three surveys.

In the 2004 and 2005 surveys, a further five items assessed job design (feedback, job control, and job content) and time pressures (inadequate time and conflicting demands). Doctors' views on the impact of the new contract were obtained from 12 items relating to GPs' perceptions of their work lives (seven items) and quality of care (five items). Prospective framing was used in the 2004 questionnaire ('Please indicate how you think the new GMS contract will affect the following issues') and retrospective in 2005 ('Please indicate how you think the new GMS contract has affected the following issues'). GPs were also asked to indicate their personal income after deduction of practice expenses and before tax; response categories were: $<£ 50$ 000, £50 000-70 000, £70 000-85000, $£ 85$ 000-100 000, £100 000-120 000, £120 000150000 , and $>£ 150000$.

\section{Statistical analysis}

Data were analysed using Stata (version 9.2). The main analysis was based on GPs' responses in 2004 and 2005, with the 2001 data used to indicate trends prior to 2004 where available. Job satisfaction and stressor scores, income, and hours worked were compared across years, with mean income estimated using midpoints of income bands with an assumed lower limit of $£ 15000$ and an 


\begin{tabular}{|c|c|c|c|c|}
\hline Characteristic & $\begin{array}{c}2001 \\
\text { sample } \\
(n=986)\end{array}$ & $\begin{array}{c}2004 \\
\text { sample } \\
(n=2105)\end{array}$ & $\begin{array}{c}2005 \\
\text { sample } \\
(n=1349)\end{array}$ & $\begin{array}{l}\text { England population } \\
\text { sample (2004) } \\
(N=28781)\end{array}$ \\
\hline \multicolumn{5}{|l|}{ Sex } \\
\hline Male & $689(70.2)$ & $1377(66.0)$ & $880(65.4)$ & 18296 (63.6) \\
\hline Female & $292(29.8)$ & $710(34.0)$ & 466 (34.6) & 10485 (36.4) \\
\hline \multicolumn{5}{|l|}{ Age, years } \\
\hline Mean (SD) & $44.9(7.3)$ & $46.9(7.4)$ & $48.6(7.1)$ & $46.4(8.9)$ \\
\hline Range & $28-78$ & $29-70$ & $31-71$ & 25-81 \\
\hline \multicolumn{5}{|l|}{ Ethnicity } \\
\hline White & $846(86.6)$ & $1762(84.6)$ & $1179(88.1)$ & - \\
\hline Non-white & $131(13.4)$ & $322(15.5)$ & 160 (12.0) & - \\
\hline \multicolumn{5}{|l|}{ Contract status } \\
\hline Principal & $942(98.1)$ & 2040 (97.8) & $1329(99.0)$ & - \\
\hline Salaried & $18(1.9)$ & $47(2.3)$ & $12(0.9)$ & - \\
\hline Locum & 0 & 0 & $1(0.1)$ & - \\
\hline
\end{tabular}

Because of item non-response the figures for sex, age, ethnicity, contract status categories differ from the total sample size. Values are $\mathrm{n}(\%)$ unless otherwise stated. ${ }^{\mathrm{a}}$ English Contracted GPs in the 2004 Database of General and Personal Medical Services Statistics England and Wales database maintained by the Department of Health. ${ }^{13}$

upper limit of $£ 200000$. Prospective and retrospective views of the impact of the new contract and experiences of job design and time pressures were also compared before and after the new contract.

Factors affecting overall job satisfaction and job pressure were investigated through ordinary least squares, fixed-effect, panel data, multiple regression models. The advantage of using a panel design is that it controls for any unobserved characteristics and gives a clearer estimate of the effect of the contract. Multiple regression allows assessment of the affect of one factor on an outcome, holding all other factors constant. The factors of interest were: income, hours worked, and hours on-call; job design and time pressures; and views on the impact of the new contract. For example, it was estimated how much more satisfied a doctor becomes on moving from a lower to a higher income band, holding hours of work, and all other job-related factors constant.

\section{RESULTS}

Table 1 compares the demographic characteristics of the survey sample with the overall population of contracted GPs in England. ${ }^{13}$ The survey sample was reasonably representative, although it tended to have fewer female GPs and a narrower age range than the overall population. In 2004, responders compared with non-responders were more likely to be female (34.2 versus $28.6 \%$ ) and younger (45.7 versus 47.8 years). There were no differences between responders and non-responders in 2005 in terms of their age (both 47.6 years) or sex (32.9 versus $34.5 \%$ female).

Doctors' mean income after expenses but before tax was estimated to have risen by just over $£ 19000$ between 2004 and 2005 (Table 2). GPs reported working fewer hours in 2005 than in 2004 but with marginally more hours on call. Table 2 also suggests that the observed downward trend in the numbers of hours worked was evident prior to the introduction of the contract, although the rate of change between 2001 and 2004 appeared to be slower. In contrast, the numbers of hours on call decreased by approximately 1.5 hours between 2001 and 2004 but increased by about 1 hour between 2004 and 2005.

Overall job satisfaction increased and overall job pressure decreased between 2004 and 2005 (Table 2). As with hours worked, the direction of change

Table 2. Job attitudes, hours of work, and income before (2004) and after (2005) the new contract. Data from 2001 included to show longitudinal trends.

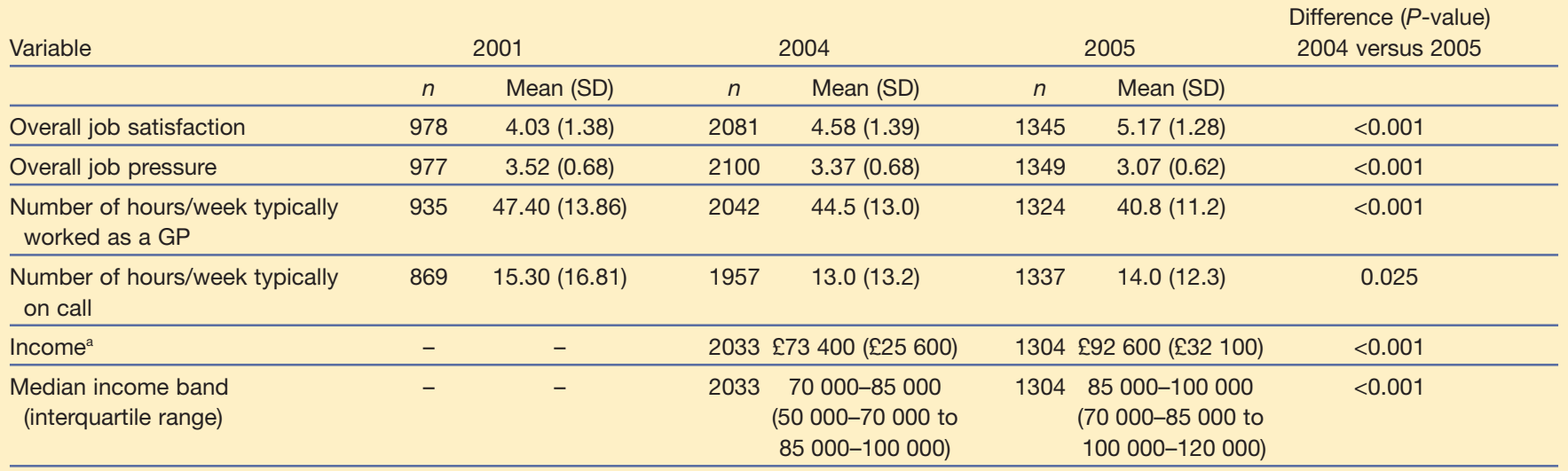

a Mean income estimated using midpoints of income bands with assumed lower limit of $£ 15000$ and upper limit of £200 000. SD = standard deviation. 
(a) Job-satisfaction scores

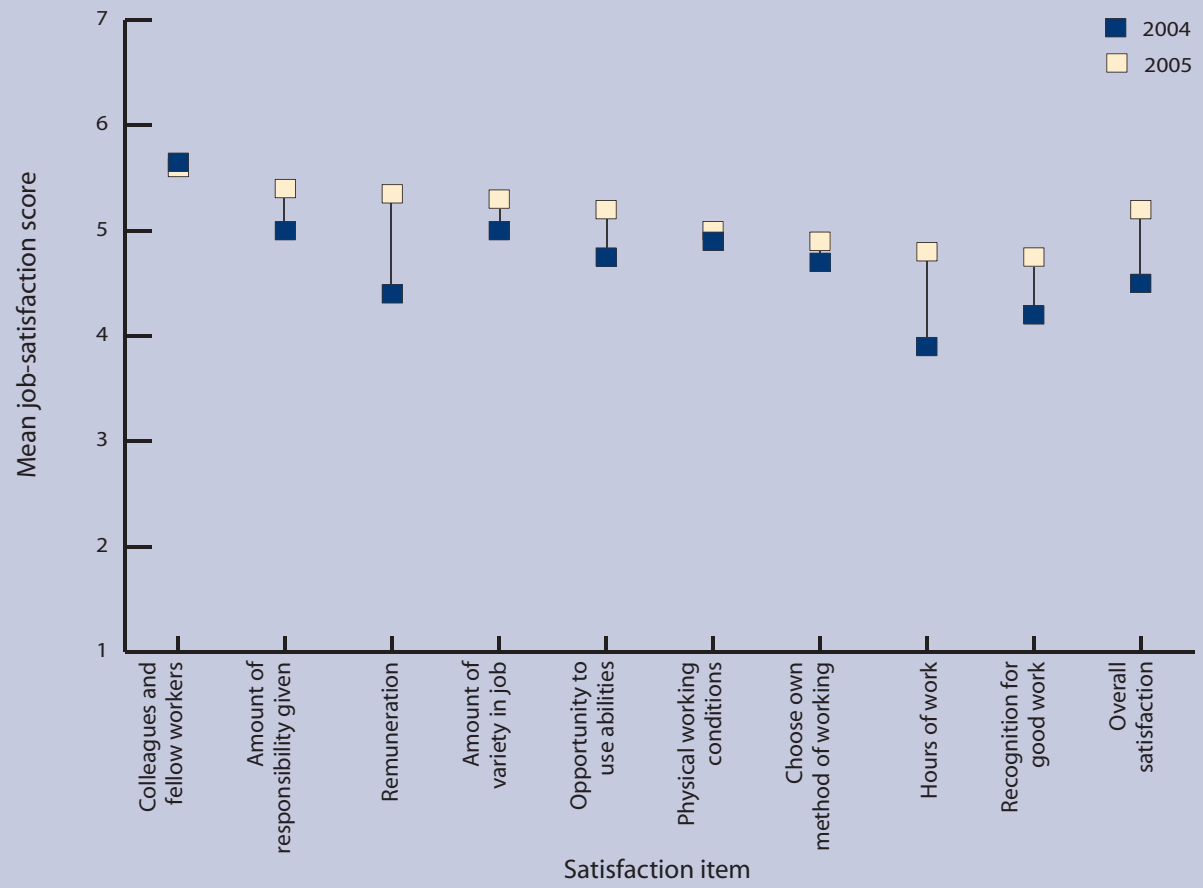

(b) Job-stressor scores

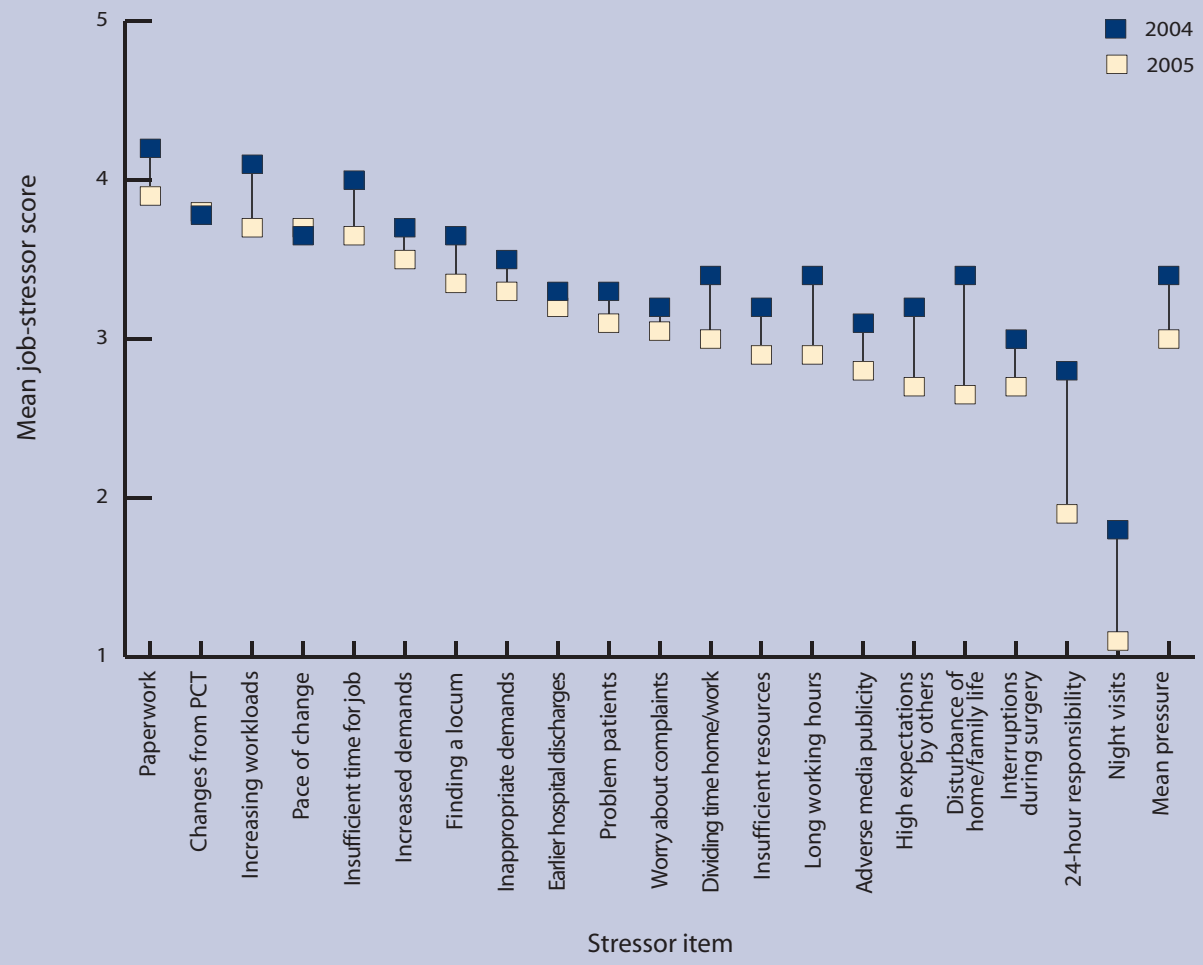

was already evident between 2001 and 2004 (Table 2). The specific aspects of job satisfaction showing the greatest improvements before and after the new contract were remuneration and hours of work (Figure 1a). The greatest reductions in pressure
Figure 1. Job

satisfaction and stressor scores before and after the contract: (a) job satisfaction; (b job stressors. 
Table 3. GPs' prospective and retrospective views of the impact of the new contract, and their experiences of job design and time pressures.

\begin{tabular}{|c|c|c|}
\hline & \multicolumn{2}{|c|}{$n / N(\%)$} \\
\hline & 2004 & 2005 \\
\hline \multicolumn{3}{|l|}{ Impact of the new contract } \\
\hline Decreased professional autonomy & 1637/1966 (83.3) & $945 / 1325(71.3)$ \\
\hline Increased clinical workload & $1819 / 2029(89.7)$ & $1143 / 1325(86.3)$ \\
\hline Increased administrative workload & $1938 / 2026(95.7)$ & $1245 / 1324(94.0)$ \\
\hline Increased personal income & $936 / 1761(53.2)$ & $1160 / 1322(87.8)$ \\
\hline Decreased ability to do justice to the job & $1079 / 1905(56.6)$ & $584 / 1319(44.3)$ \\
\hline Increased inappropriate demands from patients & $1083 / 1935(56.0)$ & $615 / 1325(46.4)$ \\
\hline Decreased overall quality of working life & $1127 / 1911(59.0)$ & $506 / 1322(38.3)$ \\
\hline Decreased quality of care for patients with acute disease & $611 / 2015(30.3)$ & 263/1325 (19.9) \\
\hline Increased quality of care for patients with chronic disease & $1430 / 2030(70.4)$ & $1038 / 1325(78.3)$ \\
\hline Increased quality of preventative care & $1379 / 2030(67.9)$ & $968 / 1324(73.1)$ \\
\hline Increased overall quality of care & $925 / 1996(46.3)$ & $800 / 1325(60.4)$ \\
\hline Increased overall quality in practice & $1008 / 1980(50.9)$ & $860 / 1324(65.0)$ \\
\hline \multicolumn{3}{|l|}{ Agreement with job design and time pressure statements } \\
\hline Job has become more interesting over last year & $391 / 2093(18.7)$ & $195 / 1344(14.5)$ \\
\hline Trouble working out if doing well or poorly & $654 / 2096(31.2)$ & $395 / 1343(29.4)$ \\
\hline Involved in deciding on changes that affect work & $925 / 2082(44.4)$ & $628 / 1341(46.8)$ \\
\hline Changes to job in last year led to better patient care & 466/2097 (22.2) & $460 / 1341(34.3)$ \\
\hline Do not have time to carry out all my work & $1644 / 2098(78.4)$ & $898 / 1343(66.9)$ \\
\hline Cannot meet conflicting demands on time at work & $1540 / 2094(73.5)$ & $857 / 1345(63.7)$ \\
\hline
\end{tabular}

Denominator (N) varies according to how many doctors responded to item.

introduced, particularly in relation to personal income, and GPs were more likely to believe that the contract had increased quality of care. Nonetheless, most responders considered that their professional autonomy had been decreased and their clinical and administrative workloads increased as a result of the contract. Despite this, fewer GPs reported having inadequate time and conflicting demands on their time in 2005 than in 2004 (Table 3).

Appendix 1 shows the results of the fixed effects panel regression models of overall job satisfaction and pressure. The coefficient for the year variable was statistically significant in both models, indicating that there were changes in satisfaction and pressure over and above that accounted for by the other measured variables. Increased satisfaction was associated with better experiences of job design and less overall job pressure, and with a more positive view on the impact of the new contract on overall quality of working life and quality of care. Hours worked and on call had no effect on job satisfaction but did increase job pressure. Job pressure increased for GPs who felt their job had become less interesting and subjected them to increased time pressure. Job pressure was also increased for GPs who reported increases in inappropriate demands from patients, reduced overall quality of working life, and reduced quality of care for acute patients.

\section{DISCUSSION}

\section{Summary of main findings}

The results of this study suggest that 18 months into the new contract, and despite the prior concerns regarding increased workloads and decreased professional autonomy, ${ }^{8}$ overall job satisfaction continued to improve, and overall job pressure declined. While doctors' views of the negative impact of the contract on workload and autonomy prevailed, the perceived gains in quality in preventive care and the care of chronic diseases exceeded their expectations and the potential negative effects on the care of acute illness were less than anticipated.

The majority of doctors in this study reported an increased income where only just over half had expected this when asked in early 2004. Doctors' mean reported income after expenses but before tax was estimated to have increased from approximately $£ 73400$ in 2004 to $£ 92600$ in 2005. This increase of $26.1 \%$ agrees well with that $(30.4 \%)$ estimated from GP tax returns for 2004 to $2005 .{ }^{17}$ At the same time, the reported number of hours worked per week was 3.7 hours less in 2005 than in 2004, continuing a decline in hours worked since 2001. 


\section{Strengths and limitations of the study}

The study had a number of limitations. The response rate to the 2004 survey was $54 \%$ and of the GPs responding in 2005, 63\% responded again in 2005. While the sample remained reasonably representative of the overall GP population in terms of demographic characteristics, the possibility that it was the least satisfied GPs who left general practice cannot be ruled out. Indeed it would be surprising if they had not, as previous research shows job satisfaction is an important predictor of intentions to quit. ${ }^{11}$ It seems unlikely, however, that the new contract had a generally negative impact on GP recruitment and retention as national census data show a higher rate of increase in the overall size of the GP workforce from 2004 to 2005 than previous years since 2001. ${ }^{18}$ In earlier surveys, job satisfaction scores appear to vary inversely with response rates: the higher the satisfaction, the lower the level of response. ${ }^{9}$ Such potential bias may affect the estimation of the level of satisfaction in any given year, but is unlikely to lead to incorrect conclusions about whether satisfaction has increased or decreased. Furthermore, similar trends in the main variables were found when scores were adjusted for variations in the sample characteristics from the underlying population and the employment of a panel design controlled for any unobserved characteristics of GPs. However, the analysis was restricted to contracted GPs, although these constitute over $90 \%$ of the workforce. ${ }^{18}$

The banded income measure was relatively crude, which could in part explain its lack of association with job satisfaction and pressure. The study was designed to evaluate GPs' subjective perceptions of the impact of the contract on various aspects of their work life and quality of care. However, such perceptions are important as it is these that affect stress and morale..$^{19,20}$

\section{Comparison with existing literature}

The apparent discrepancy between the decrease in hours worked and GPs' perceptions of increased clinical and administrative workloads could be a function of the difference between objective workload (that is, time spent on work), job weight (that is, intensity or difficulty of work) and subjective workload (that is, feelings of overwork). ${ }^{21}$ GPs' job weight may have increased (for example, routine care may be delegated to nurses leaving GPs with complex problems) and so increased their subjective workload. It could well be that the increase in income allowed some GPs to decrease their time commitment, so as to be able to cope better with the increased subjective workload. Free-text comments on the questionnaire indicated that at least some doctors had taken this option. It is also not known how many hours doctors work beyond the typical working week, for example, by doing paperwork at home in the evenings and at weekends. Nor is it known whether such activities were included in their reported number of hours worked.

It could be argued that the increased income and reduced working hours reported by GPs has gone some way towards compensating them for the perceived increased subjective workload and loss of autonomy, thereby increasing overall job satisfaction. The results of the multivariate analysis suggest that decreased hours of work was strongly associated with reduced job pressure which was in turn associated with higher job satisfaction. However, increased remuneration was not associated with either job satisfaction or pressure after controlling for other factors. Such findings concur with previous assertions that workload and pay, although undoubtedly important, do not by themselves ensure high morale. ${ }^{22}$ Psychological theory suggests that while inadequate income can bring about dissatisfaction, it is not a satisfier in itself. ${ }^{23}$ Other studies have suggested that people have target incomes, over which any increase has less effect on satisfaction. ${ }^{24}$

Doctors reported the new contract had a more favourable impact on quality of care than they had anticipated prior to its introduction.

\section{Implications for future research}

GPs report that the new contract has increased their workload and decreased their professional autonomy but also increased their income. Eighteen months into the new contract, it would appear that this has been an acceptable trade for doctors: job satisfaction has risen and job pressure fallen, continuing - if not accelerating - improvements already evident between 2001 and early 2004. At the same time, GPs' expectations regarding the likely impact of the contract on their quality of care have been exceeded and other research shows improved overall performance in general practice. ${ }^{25}$ The contract could therefore be said to have achieved its stated aims of improving both GPs' working lives and their quality of care.

However, any evaluation of the success of the new contract from a policy perspective must consider the benefits obtained (for example, the likely health gain $)^{26}$ in return for the cost of the incentives. There are concerns that the new contract has penalised practices serving deprived populations and detracted from person-centred care..$^{27,28}$ It also remains to be seen whether morale is maintained as doctors become accustomed to their new earnings and as further adjustments are made to the QOF. 


\section{Funding body}

The study forms part of the core research programme of the National Primary Care Research and Development, which is funded by the Department of Health. The views expressed are those of the authors and do not necessarily reflect those of the Department of Health

\section{Ethical approval}

The study was granted exempt status by the North West NHS Multi-centre Research Ethics Committee

\section{Competing interests}

The National Primary Care Research and Development Centre played a significant role in developing many of the performance indicators included in the QOF of 2004

\section{Acknowledgements}

We are grateful to the many GPs who took the time to participate in this research

\section{Discuss this article}

Contribute and read comments about this article on the Discussion Forum: http://www.rcgp.org.uk/bjgp-discuss

\section{REFERENCES}

1. Shekelle P. New contract for general practitioners. BMJ 2003; 326(7387): 457-458.

2. NHS Confederation. Investing in general practice - the new general medical services contract. 2003.

3. Spurgeon P, Hicks C, Field S, Barwell F. The new GMS contract: impact and implications for managing the changes. Health Serv Manage Res 2005; 18(2): 75-85.

4. Campbell SM, Roland MO, Middleton E, Reeves D. Improvements in quality of clinical care in English general practice 1998-2003: longitudinal observational study. BMJ 2005; 331(7525): 1121.

5. Leslie SJ, McKee SP, Imray EA, Denvir MA. Management of chronic heart failure: perceived needs of general practitioners in light of the new general medical services contract. Postgrad Med J 2005; 81(955): 321-326.

6. Roland M. Linking physicians' pay to the quality of care - a major experiment in the United Kingdom. N Engl J Med 2004; 351(14): 1448-1454.

7. Epstein AM, Lee TH, Hamel MB. Paying physicians for highquality care. N Engl J Med 2004; 350(4): 406-410.

8. Whalley D, Bojke C, Gravelle H, Sibbald B. 2004 National survey of general practitioner job satisfaction: final project report. Manchester: NPCRDC, 2005.

9. Whalley D, Bojke C, Gravelle H, Sibbald B. GP job satisfaction in view of contract reform: a national survey. Br J Gen Pract 2006; 56(523): 87-92.

10. Marshall M, Roland M. The new contract: renaissance or requiem for general practice? Br J Gen Pract 2002; 52(480): 531-532.

11. Sibbald B, Bojke C, Gravelle H. National survey of job satisfaction and retirement intentions among general practitioners in England. BMJ 2003; 326(7379): 22.

12. Department of Health. General and Personal Medical Services Statistics England and Wales 2002. http://www.primary-caredb.org.uk/

13. Department of Health. General and Personal Medical Services Statistics England and Wales 2004. http://www.primary-caredb.org.uk/

14. Warr P, Cook J, Wall T. Scales for the measurement of some work attitudes and aspects of psychological well-being. Journal of Occupational Psychology 1979; 52(2): 129-148.

15. Sutherland VJ, Cooper CL. Job stress, satisfaction, and mental health among general practitioners before and after introduction of new contract. BMJ 1992; 304(6841): 1545-1548.

16. Sibbald B, Enzer I, Cooper C, et al. GP job satisfaction in 1987 1990 and 1998: lessons for the future? Fam Pract 2000; 17(5): 364-371.

17. The Information Centre. GP earning and expenses 2004/05. http://www.ic.nhs.uk/statistics-and-datacollections/workforce/nhs-staff-earnings/gp-earnings-andexpenses-2004-05 (accessed 20 Nov 2007).

18. The Information Centre. General and Personal Medical Statistics in England: 1995-2005. http://www.ic.nhs.uk/statistics-and-datacollections/workforce/nhs-numbers/nhs-staff-1995--2005. (accessed 20 Nov 2007).

19. Grieve $\mathrm{S}$. Measuring morale - does practice area deprivation affect doctors' well-being? Br J Gen Pract 1997; 47(422): 547-552.

20. Spurgeon P, Barwell F, Maxwell R. Types of work stress and implications for the role of general practitioners. Health Serv Manage Res 1995; 8(3): 186-197.

21. Groenewegen PP, Hutten JB. Workload and job satisfaction among general practitioners: a review of the literature. Soc Sci Med 1991; 32(10): 1111-1119.

22. Edwards N, Kornacki MJ, Silversin J. Unhappy doctors: what are the causes and what can be done? BMJ 2002; 324(7341): $835-838$.

23. Herzberg F, Mausner B, Snyderman B. The motivation to work 2nd edn. New York: Wiley; 1959.

24. Drakopoulos SA, Theodossiou I. Job satisfaction and target earnings. J Econ Psychol 1997; 18(6): 693-704.

25. Campbell S, Reeves D, Kontopantelis E, et al. Quality of primary care in England with the introduction of pay for performance. $N$ Engl J Med 2007; 357(2): 181-190.

26. Fleetcroft R, Cookson R. Do the incentive payments in the new NHS contract for primary care reflect likely population health gains? J Health Serv Res Policy 2006; 11(1): 27-31.

27. Guthrie B, McLean G, Sutton M. Workload and reward in the Quality and Outcomes Framework of the 2004 general practice contract. Br J Gen Pract 2006; 56(532): 836-841.

28. Freeman G. Up close and personal? Continuing pressure on the doctor-patient relationship in the QOF era. Br J Gen Pract 2006; 56(528): 483-484. 


\section{Appendix 1. Fixed effects regression model of overall job satisfaction and job pressure}

Regression coefficient (95\% Cl)

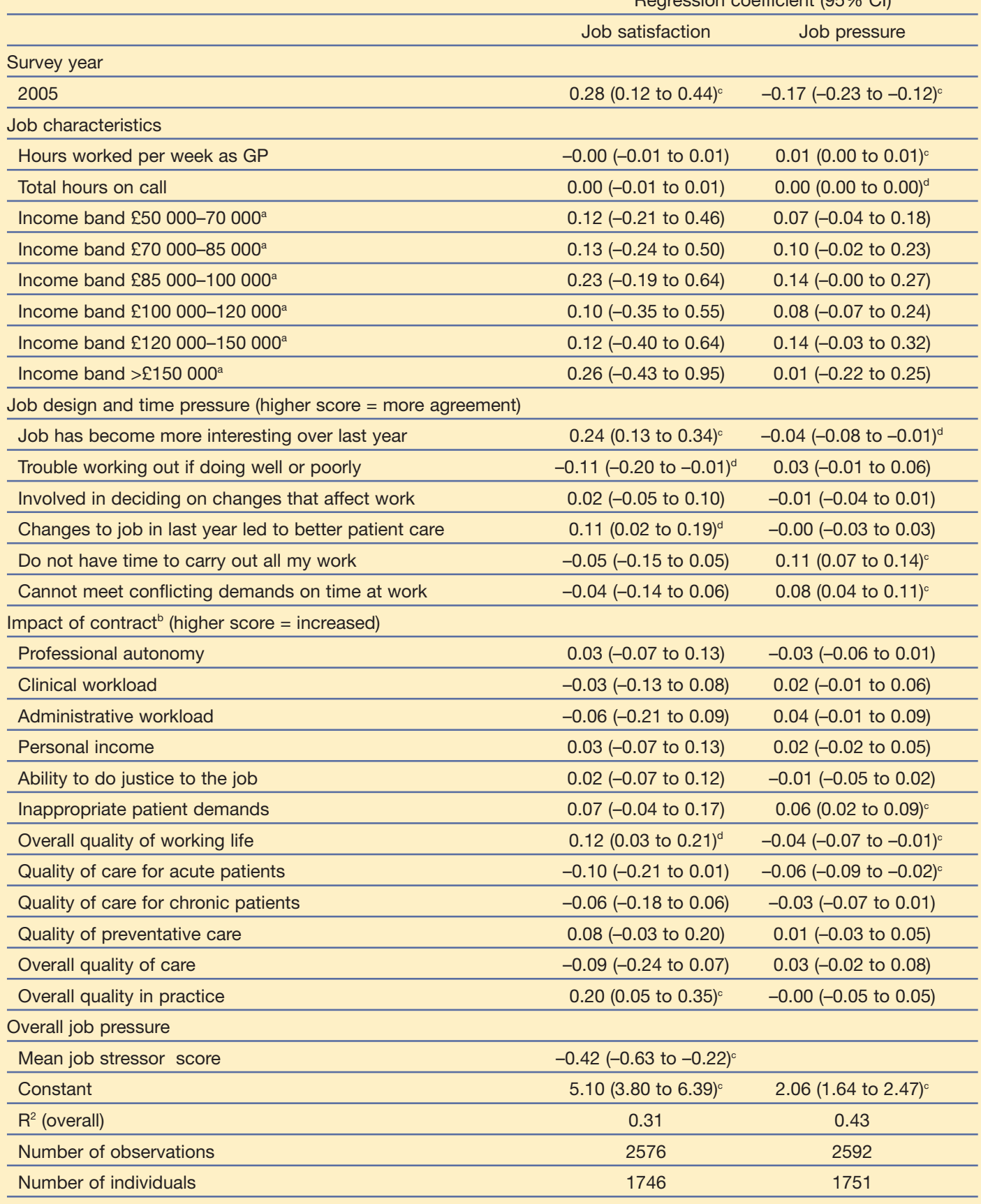

a/ncome band $<£ 50000$ excluded. ${ }^{b}$ Prospective in 2004 , retrospective in $2005 .{ }^{c} \mathrm{P}<0.01 .{ }^{\mathrm{d}} \mathrm{P}<0.05$. 